\title{
Procedures and Techniques Used to Increase the Durability of Weak Masonries with Clay Mortars
}

\author{
Daniel Covatariu ${ }^{1,}$, Mihai Budescu ${ }^{2}$, Nicolae Ţăranu ${ }^{3}$, Irina Lungu ${ }^{4}$, \\ Ionuţ-Ovidiu Toma ${ }^{5}$ \\ 1,2,3,4,5“Gheorghe Asachi” Technical University from laşi, Faculty of Civil Engineering and Building \\ Services, Romania \\ accovadan@ce.tuiasi.ro (corresponding author)
}

Keywords: low-strength mortars, masonry durability, damaged historical masonry, reinforcing fibres, improved joints

\begin{abstract}
For the past decades the importance of structural rehabilitation of historical buildings, in order to preserve the cultural heritage, has increased considerably. The weak masonry (made from bricks and bounded with low-strength mortars) were created using mortars which, depending on different external factors, were degraded and there are necessary urgent rehabilitation interventions in order to assure the masonry's durability by protecting the joints with new, compatible and reversible materials and techniques (according to Venice charter requirements). In order to increase the durability characteristics of the weak masonry, the design and application techniques of some particular materials and solutions used will be considered in present paper. The used procedures are based on joints reinforcing using fibre reinforced mortar (fibres made of steel, carbon and glass). The test results have revealed a significant improvement of the structural response and a noticeable increased durability depending on the materials and techniques used.
\end{abstract}

\section{Introduction}

Ever since ancient times the masonry buildings have been based on local materials, such as stone and ceramic brick units bonded with mortars of various mixtures. Except for the dry masonry, the utilized mortars were based on local natural resources.

It is important to understand that the life span as well as the environmental factors such as: water and freeze-thaw cycles, differential settlements accompanied occasionally by extraordinary actions including earthquakes and windstorms, produce permanent deteriorations on masonry buildings, imposing remedial actions, restoration or reconstruction.

Our current actions, trying to preserve the vestiges of the past, have been a concern since ancient times; the roots of this approach can be found in the Western Europe, even since Roman antiquity, continued into the Middle Ages when the first "laws" related to the preservation and protection of monuments have been issued. Later on, during the Renaissance period followed by the late nineteenth and the beginning of the twentieth century the foundations of scientific restoration of historical monuments, based on the notion of authenticity initiated by Camillo Boito (1835-1914) and completed by the Venice Charter Conservation and Restoration of Monuments (1964) have been elaborated $[1,2]$.

The scientific basis for interventions on heritage old buildings has undergone many conceptual changes over time and there are few who believe that existing remedial solutions will not be later altered. Therefore the current concept of sustainable construction should include the idea of reversibility caused by the daily changes, resulting from the emerging of new technologies and material properties that are becoming more efficient. In addition, the evolution of human thinking has also generated and accelerated new transformations in the recent years [3].

It can be realized from the current practice that the concept of reversibility is almost entirely neglected in case of monument restoration. 
It can be envisaged that some future technological approaches might eliminate the current strengthening solutions and replace them with new ones, able to preserve more of monuments identity. This is possible only if the present procedures utilized nowadays would preserve the original integrity of the system and the reversibility is possible.

Any rehabilitation system should be adjacently connected to the basic structure using links that can be easily removed without damaging the substrate.

The specialized literature describes various methods of improving the building safety utilizing adjacent means such those made of steel or reinforced concrete elements, involved with the sole purpose to preserve the "temporary integrity" while maintaining the reversibility. Since these procedures might sometimes be too expensive, any other solution that preserves the basic principles of reversibility could be a viable alternative $[1,2,3]$.

Research works carried out nationally and internationally have been focused on the rehabilitation of historical masonry following two main directions [4]:

1. rehabilitation using traditional building materials by:

- fully replacing the deteriorated parts;

- re-pointing the mortar joints with compatible material;

- strengthening of joints with rigid reinforcing bars;

- caulking, injecting as well as using steel dogs across the cracks;

2. rehabilitation by surface treatments:

- jacketing the masonry units with cement-based mortars and/or ferocement reinforced with various materials (wire meshes, individual reinforcing elements);

- attachment of adjacent elements made of steel, wood, reinforced concrete or composite materials to the main framing system.

Some of the processes mentioned above do not take into account the principle of reversibility, material compatibility and minimal interference on the structure, occasionally causing deteriorations even more severe than the original ones.

Regardless of the damaging factors causing the deterioration of masonry, it is necessary that the material used for their rehabilitation or strengthening should comply with the two apparently opposite requirements $[5,6,7]$ :

- it should be sufficiently porous (to enable the drying out of the walls) and mechanically compatible with the original materials;

- despite its porosity, the material should not be vulnerable to the aggressive external attacks (rain, frost, polluted air) or inside the masonry elements (due to sulphates and alkali-reactive components).

In addition to the above mentioned factors the amount of water used in mixtures that can interact with the compounds of the degraded structure should be considered. A number of pollutants within water or atmosphere can react and lead to the formation of salts with adverse effects on the masonry similar to the freeze-thaw cycles and changes of the mechanical characteristics.

Typical degradation caused by corrosive effects of these salts is materialized in the wall efflorescence produced by crystallization volume growth, that can cause irreversible damage to finishes, frescoes and murals that are found frequently in masonry buildings of historical heritage.

There are currently no mortars for the masonry joints that would simultaneously satisfy the two above mentioned conditions. Therefore in this paper several new concepts/solutions are analyzed and implemented and they partially improve the material of masonry joints. Since the overall behaviour of the masonry structural system is critically dependent on the mortar-brick interface, the proposed solutions will ensure the integrity of the existing structural system in terms of joint material, on a span life larger than the regular 25 years service period.

\section{The joint strengthening procedure}

The paper presents new approaches to the rehabilitation techniques using fibre reinforced mortars that join the masonry units; the types of fibres that have been analyzed and tested are: carbon, glass and steel fibres as well as polypropylene textile chords [6]. 
In this way the following improvements are envisaged:

- increased long term resistance of the masonry joints utilizing sustainable fibre reinforced materials;

- increased load bearing capacity of masonry against horizontal actions, and improved energy dissipation capacity of the joint materials;

- increasing the durability of the strengthened masonry by using materials that can protect the joints against environmental aggressive agents;

- increased bonding between the masonry units and protection of the joint infill mortar, against the friability of the clay mortar.

\section{Materials used for the masonry joints strengthening}

Several panel type specimens have been conceived and manufactured to perform the tests. The reinforcing of the masonry joints has been achieved using the following coated fibre products: glass fibres (MapeWrap G Fiocco, fig. 1a), carbon fibres (MapeWrap C Fiocco, fig. 1c), steel fibres (MapeWrap Steel, fig. 1b) and regular polypropylene yarns (fig. 1d). The external chord diameter including the protective mesh is $10 \mathrm{~mm}$ for the first three fibrous products and $4 \mathrm{~mm}$ for the textile yarns (requiring the of three twisted strings within the joints). The main characteristics of these materials are given in Table 1.

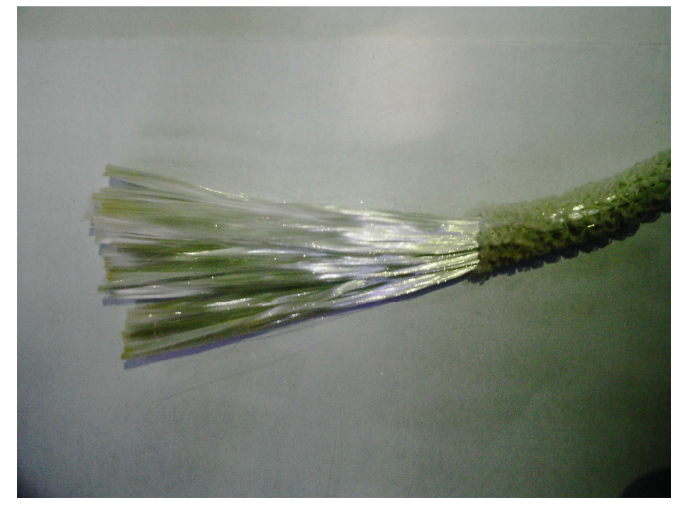

a.

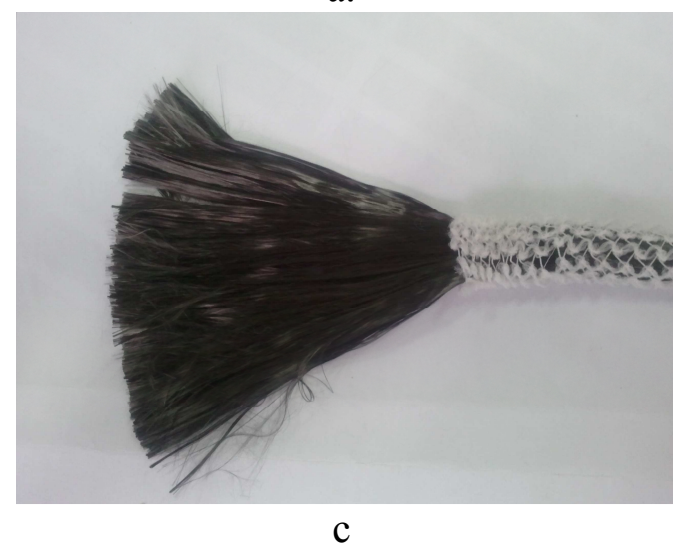

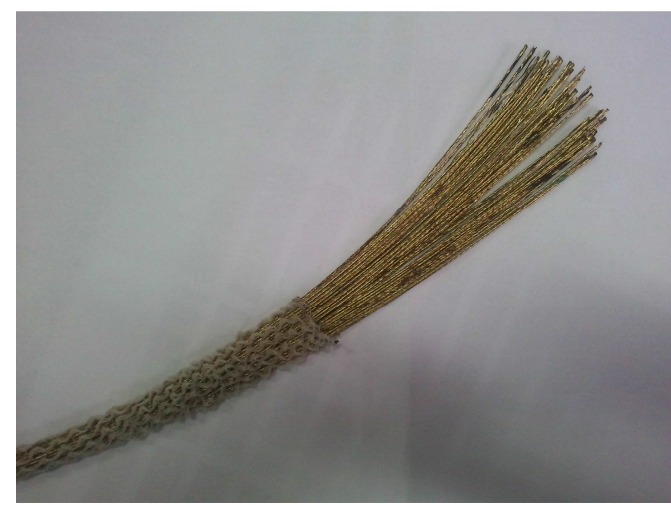

b.

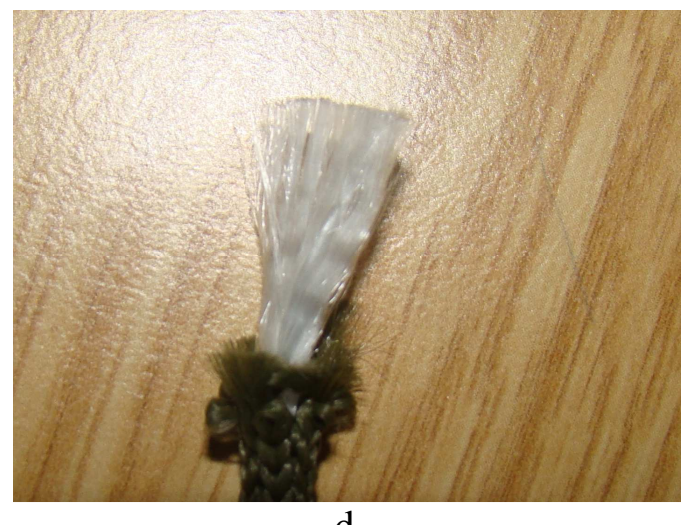

d

Fig.1 The fibres utilized for the flexible reinforcing of the joints a. glass fibres, b. steel fibres, c. carbon fibres, d. polypropylene textile fibres

Specific laboratory tests have been performed to evaluate the physical and mechanical characteristics for each type of the material used in the strengthening solutions [8, 9,10-14].

An adherence mortar type M10Z with ECO-CEMENT (SR-EN 197-1:2002) type CEM II / BM (S-LL) $42.5 \mathrm{~N}$ has been used for the joint re-pointing. 
Table 1. Principal characteristics of the chords used for the joint reinforcing

\begin{tabular}{|l|c|c|c|}
\hline Material & MapeWrap C & MapeWrap G & MapeWrap S \\
\hline Fibre type & carbon & E-glass & steel \\
\hline Density $\left(\mathrm{g} / \mathrm{cm}^{3}\right)$ & 1.8 & 2.62 & 4.84 \\
\hline Tensile strength $\left(\mathrm{N} / \mathrm{mm}^{2}\right)$ & 4830 & 2560 & 2086 \\
\hline Elasticity modulus $\left(\mathrm{N} / \mathrm{mm}^{2}\right):$ & 230,000 & 80,700 & 210,000 \\
\hline Ultimate tensile strain $(\%):$ & 2 & $>3$ & $>2$ \\
\hline Equivalent fibres area $\left(\mathrm{mm}^{2}\right)$ & 26.79 & 27.58 & \\
\hline
\end{tabular}

\section{Preparation of test specimens}

The experimental panels used in the research program have been made of brick units extracted from a masonry structure built in the early twentieth century; the bricks dimensions were 240x120x80 mm and the clay mortar has been applied in layers of about 10-15 mm thick.

15 specimens (two bricks long, one brick wide and a depth equal to five brick thicknesses) have been manufactured to be tested in compression.

A plain leveling layer of cement mortar has been applied on the top of panel type specimen to ensure the flatness during testing, fig.2.

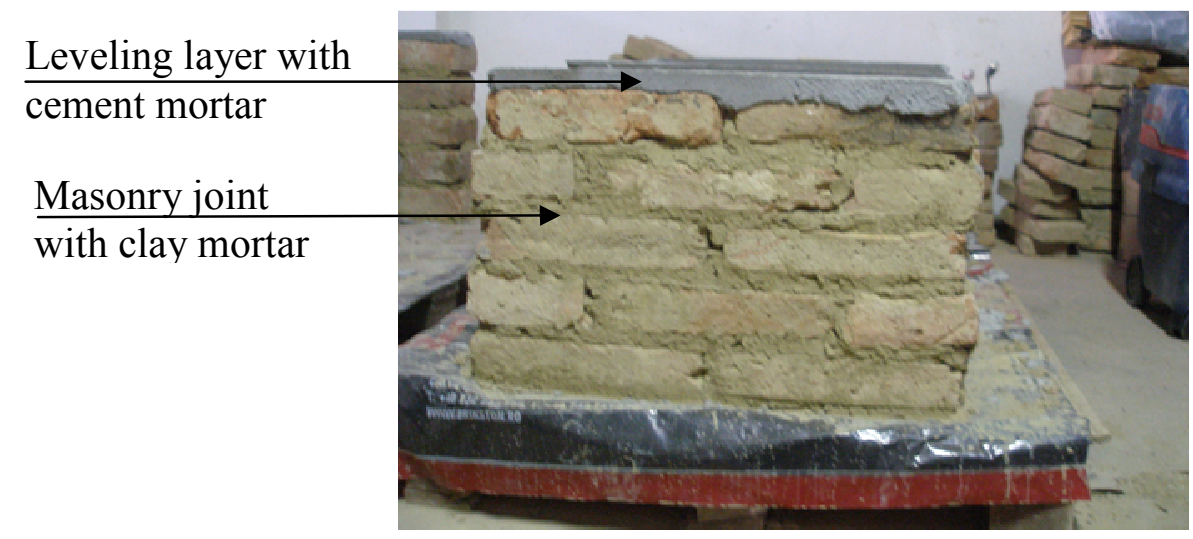

Fig. 2 The witness/control specimen for compression testing

The test specimens were kept under laboratory conditions while three specimens have been assigned as control samples. The other 12 panels were prepared for the joint re-pointing procedure. The joints, on both sides (fig.3), have been capped to a depth of $25 \mathrm{~mm}$, cleaned of dust and primed with mortar; after this, the chord type fibre reinforcement has been inserted and covered with M10Z mortar (fig. 4).

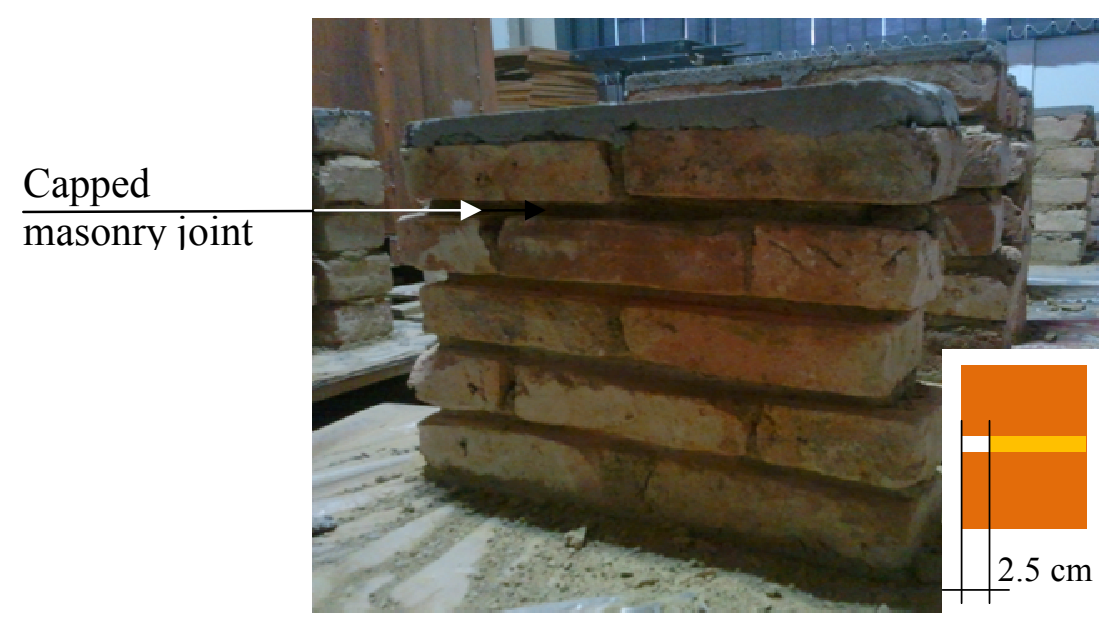

Fig.3 The specimen with $25 \mathrm{~mm}$ joint capping 


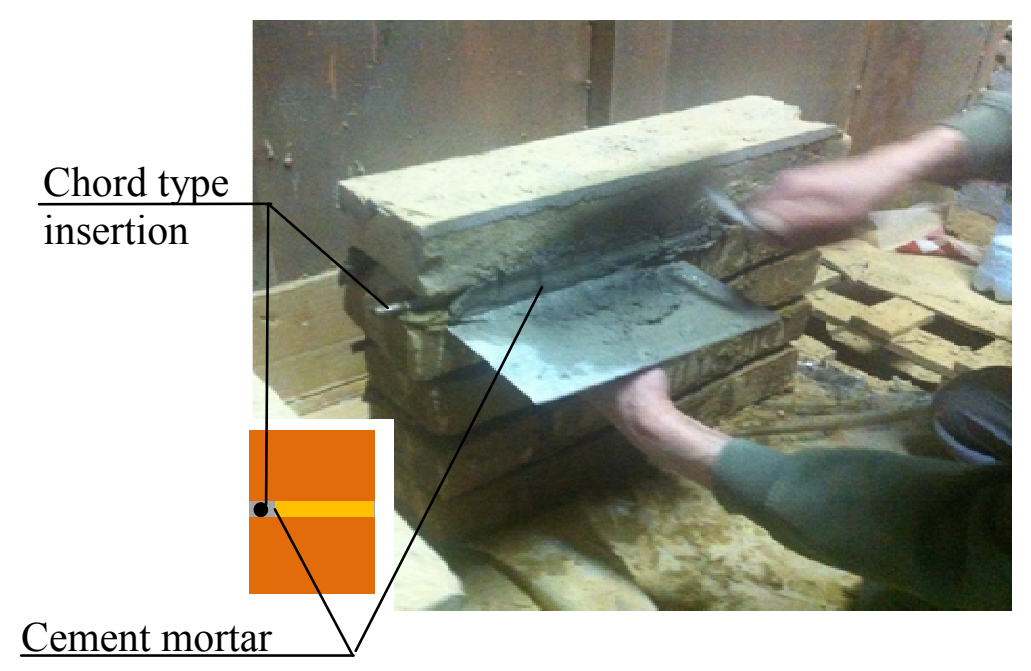

Fig.4 Disposal of the chords and mortar within the specimen joints

For each of the fibre chords (Fig. 1) groups of 3 samples were prepared by joint priming with M10Z mortar and insertion of the corresponding ropes.

\section{Testing procedure of specimens}

The experimental program consisted of testing all 15 specimens loaded in compression utilizing a universal testing machine of $3000 \mathrm{kN}$ load capacity. A special load cell (Fig. 5) equipped with electrical strain gauges has been utilized to ensure precise reading needed during the experimental program.

The deformations undergone by the compressed specimens have been recorded using 4 Linear Voltage Displacement Transducers (LVDTs) placed symmetrically on each side (Fig. 5). Their positions have been assigned on the central portions of the masonry panels. The instalment of the transducers has been specially chosen to enable the loading up to the specimen failure. The distance between the measuring points corresponds to the interval between four layers of mortar. Each test has been performed until the specimen failure.

A specialized data acquisition and processing system has been utilized during the experimental program, providing a speedy interpretation of the results.

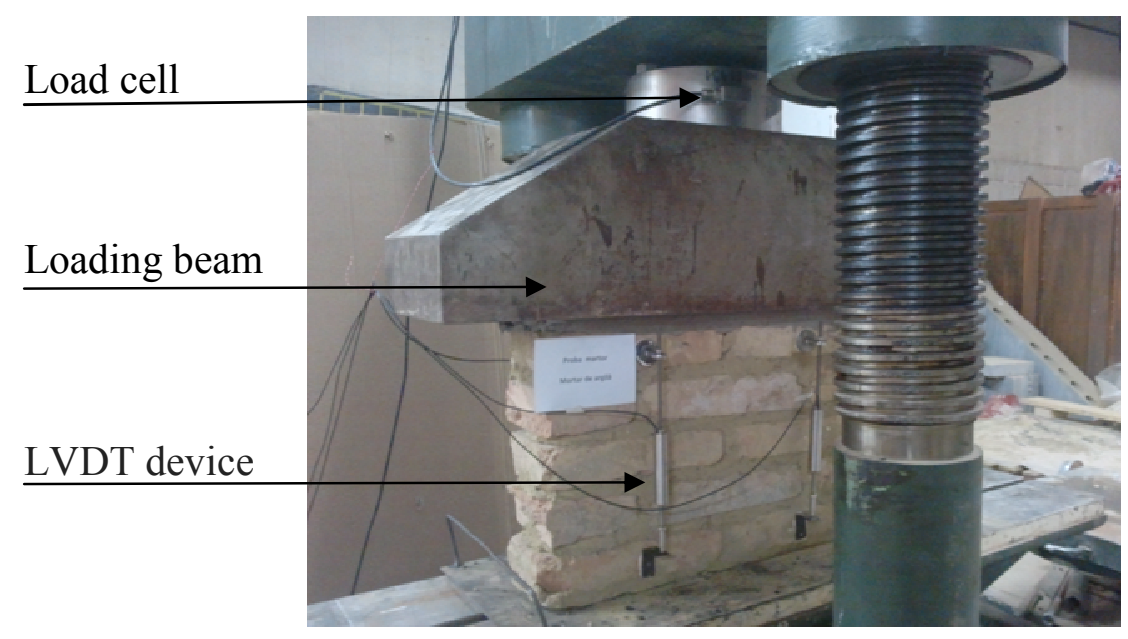

Fig.5 The instrumentation of the specimen

\section{The experimental results}

The average values of the ultimate axial compressive forces are presented in Table 2. Some typical failure modes are illustrated in Figures $6 \div 10$. 

Innovation for Sustainable Development

Table 2 - Experimental results on the compressed samples with reinforced joints

\begin{tabular}{|c|c|c|c|c|c|}
\hline \multirow{3}{*}{ Specimen } & \multicolumn{5}{|c|}{ Failure load [kN] } \\
\cline { 2 - 6 } & \multirow{2}{*}{$\begin{array}{c}\text { Control } \\
\text { sample }\end{array}$} & Glass fibres & Carbon fibres & Steel fibres & Polypropylene \\
\cline { 3 - 6 } & 150 & 220 & 200 & 250 & 270 \\
\hline 1 & 170 & 260 & 200 & 310 & 270 \\
\hline 2 & 190 & 245 & 207 & 250 & 290 \\
\hline 3 & & \multicolumn{5}{|c|}{} \\
\hline
\end{tabular}
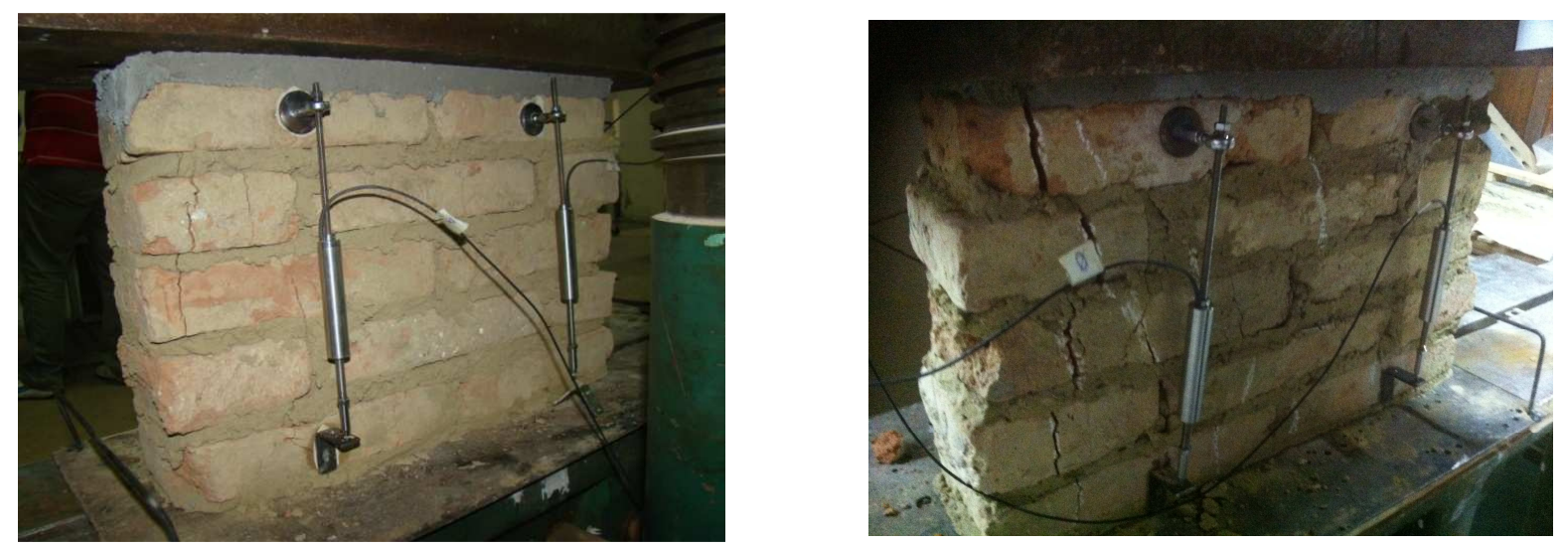

Fig.6 The failure mode of the witness/control specimen

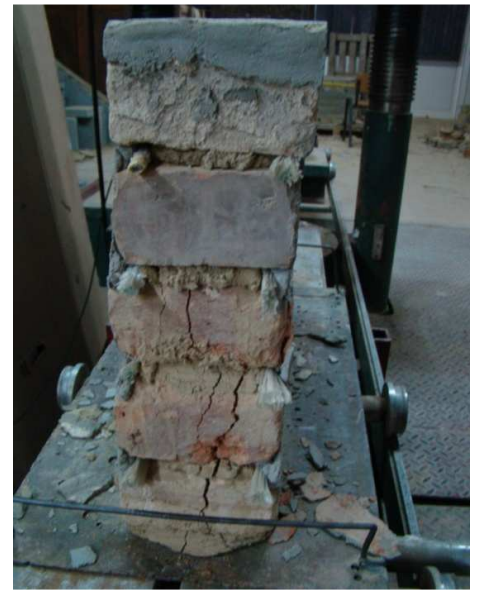

Fig.7 The failure mode of the specimen with joints reinforced with glass fibres chord

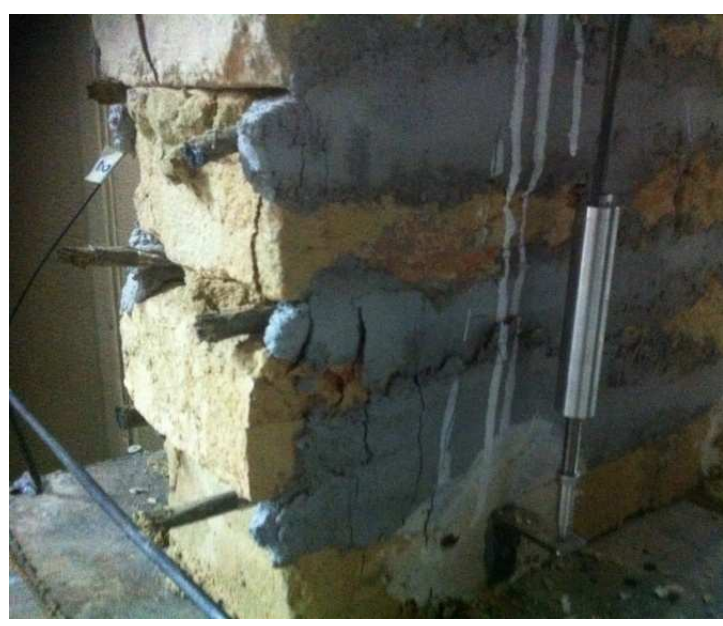

Fig.9 The failure mode of the specimen with joints reinforced with steel fibres chord

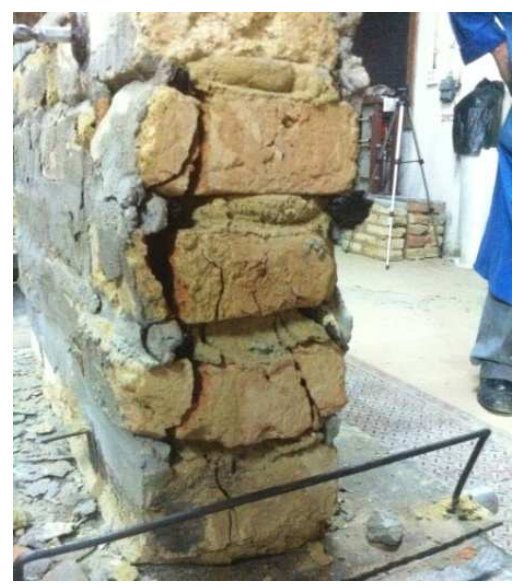

Fig. 8 The failure mode of the specimen with joints reinforced with carbon fibres chord

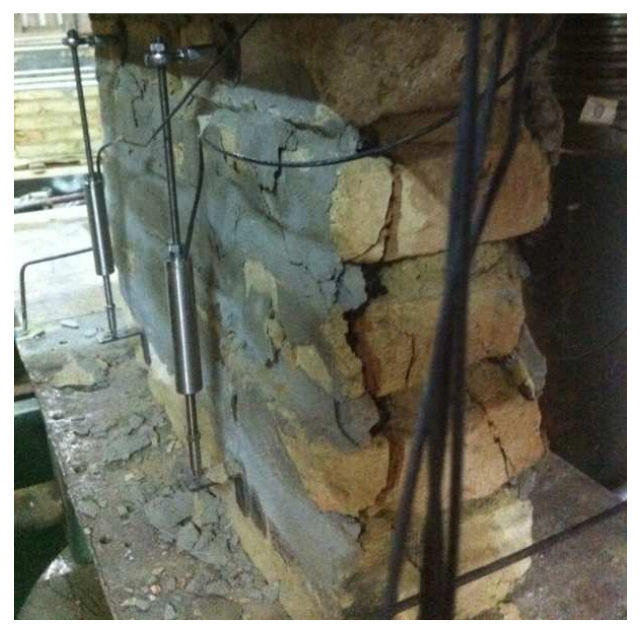

Fig.10 The failure mode of the specimen with joints reinforced with 3 polypropylene strings 


\section{Conclusions}

The load bearing capacities of the control specimens are different due to the non-uniformity of the material properties utilized in masonry panels (the source of the brick units from various locations of the initial building).

The failure of all masonry control specimens is characterized by large cracks penetrating the whole structure.

A significant increase of the load bearing capacity has been obtained by inserting within the joints various chords covered with eco-mortars.

The failure modes of the reinforced joint masonry differs from those observed on the control specimens, namely with vertically developed cracks near the joint reinforced area, with a less affected central area.

Comparing the structural response of the tested masonry panels a substantial increase in rigidity of the reinforced samples has been achieved with respect to the control specimens.

The polypropylene fibre insertion resulted in higher resistance and less increase in stiffness, but a more convenient cost-effective solution.

\section{ACKNOWLEDGEMENTS}

This paper was supported by the project "Develop and support multidisciplinary postdoctoral programs in primordial technical areas of national strategy of the research - development innovation" 4D-POSTDOC, contract nr. POSDRU/89/1.5/S/52603, project co-funded from European Social Fund through Sectorial Operational Program Human Resources 2007-2013.

\section{References}

[1] Tinazzi Davide, Nanni Antonio (2000), Assesement of Techonologies of Masonry Retrofitting with FRP, 148 pp, University of Missouri-Rolla, Center For Infrastructure Engineering Studies

[2] Caspar Groot (2012), Developments On Repointing Of Salt-Laden Historic Masonry in the Netherlands, in Proceedings of CIRea2012 - International Conference on Rehabilitation of Ancient Masonry Structures, Lisabon, ISBN: 978-989-20-3080-7, pp 5-15

[3] Luque A., Cultrone G. and Sebastián E (2010), The Use of Lime Mortars in Restoration Work on Architectural Heritage, pp. 197-207, in "Materials, Technologies and Practice in Historic Heritage Structures", Springer Science+Business Media B.V., ISBN 8-90-481-2684-2

[4] Pleşu R., Ţăranu G., Covatariu D., Grădinariu I.D. (2011) Strengthening and Rehabilitation Conventional Methods for Masonry Construction, The Bulletin Of The Polytechnic Institute Of Jassy, Construction. Architecture Section, ISSN: 1224-3884, E-ISSN: 2068-4762, Tomme: LVII (LXI), Fascicle: 4, pp. 165-176;

[5] Covatariu D., Toma I.O., Budescu M. (2011), Experimental Investigation on Bonding Characteristics of Low-Strength Mortars Used to Repoint the Joints of the Damaged Historical Masonry Structures, The Bulletin of the Polytechnic Institute of Jassy, Construction. Architecture Section, ISSN: 1224-3884, e-ISSN: 2068-4762, Tomme: LVII (LXI), Fascicle: 2, pp. 59-68

[6] Covatariu D., Toma I.O., Pleşu R., Budescu M. (2011), A Study on Mortar Adherence to Masonry Pieces In Case of Historical Buildings, paper: CT7-14, ISBN: 978-989-654-079-1, http://193.136.66.103/iceubi2011/home, ICEUBI2011 - International Conference on Engineering UBI 2011 - "Innovation and Development", Covilha, Portugalia

[7] Covatariu D., Budescu M. (2012), Investigation on Adherence Characteristics of LowStrength Mortars Used in the Damaged Historical Masonry Structures, Proceedings of the $8^{\text {th }}$ International Conference on Structural Analysis of Historical Constructions, SAHC 2012, Wroclaw, Poland, ISBN 978-83-7125-218-1, vol. II, pp: 1797-1803, http://sahc2012.org/index.html 
[8] Budescu M., ş.a., Material Testing, Technical Publishing House, Bucharest, cap. 21, pg. 389 415, 1982

[9] ENV -1-1, Eurocode 6: Design of masonry structures - Part 1-1: General rules for buildings Rules for Reinforced and Unreinforced Masonry

[10] PROCEMA S.A. Bucharest (1999), Investigation methodology of old masonries - index MP007-99

[11] CSA A179-04, CSA (Canadian Standards Association) (2004), Mortar and Grout for Unit Masonry

[12] ASTM C1357-09 (2009), Standard Test Methods for Evaluating Masonry Bond Strength

[13] ASTM C780-10 (2010), Standard Test Method for Preconstruction and Construction Evaluation of Mortars for Plain and Reinforced Unit Masonry

[14] ASTM C270 - 10 (2010), Standard Specification for Mortar for Unit Masonry 